\title{
A TEMÁTICA SEXUALIDADE EM ATIVIDADES EXTENSIONISTAS: UM ESTUDO EM UMA UNIVERSIDADE BRASILEIRA
}

\author{
THE SEXUALITY THEME IN EXTENSION ACTIVITIES: A STUDY IN A \\ BRAZILIAN UNIVERSITY
}

\author{
Wellington Soares de Lima ${ }^{1}$ \\ Lourdes Aparecida Della Justina ${ }^{2}$
}

\begin{abstract}
Resumo: No meio acadêmico, além de se estudar sexualidade, deve-se encontrar meios de divulgação e de democratização de saberes relacionados. Esses saberes podem ser propagados mediante o desenvolvimento de atividades de extensão universitária. Nessa perspectiva, o objetivo do estudo em questão foi investigar como a sexualidade é trabalhada em uma universidade brasileira, de forma extensionista. $\mathrm{O}$ estudo foi realizado por meio de análises das informações em sistemas informatizados de atividades de extensão da universidade investigada. No levantamento foram selecionadas 54 atividades no período de 2003 a 2018. Iniciamos observando a amplitude das atividades quanto às suas tipologias e às variações de propostas ao longo dos anos. Posteriormente, foram identificadas suas áreas de conhecimento, seus respectivos públicos-alvo e objetivos. A avaliação é que as atividades se destacam dentro do viés social, e se preocupam, em especial, com a formação continuada docente, a qual pode formar multiplicadores de saberes.
\end{abstract}

Palavras-chave: Educação sexual; Gênero; Extensão.

\begin{abstract}
Sexuality is a present theme in people routine in different spheres and institutions. According to it, in the academic environment, besides studying the theme it is needed to find ways to spread the knowledge which can be propagated through the extension activities. Following this perspective, the present paper intends to investigate how the sexuality is approached in a Brazilian university, regarding the extensionist sphere. The study was made using system computerized data about the investigated university extension activities. By the end of the survey, 54 activities were analyzed from 2003 to 2018 . We started observing the activities amplitude regarding their typologies and proposals variations all over the years. After this, we identified the knowledge areas and also their respective audience and goals. The evaluation is that the activities are highlighted within the social scope and aim, specially, the teachers continuous education that can enable these ones to be knowledge multipliers.
\end{abstract}

Keywords: Sexual Education; Genre; Extension.

\section{A extensão universitária e a temática sexualidade}

A temática sexualidade é discutida em diversas mídias e instituições sociais, cabendo também à universidade discutir tal temática e apresentar à comunidade suas

\footnotetext{
${ }^{1}$ Mestre em Educação pela Universidade Estadual do Oeste do Paraná (Unioeste). Secretaria de Estado da Educação (SEED), Cascavel, Paraná, Brasil. E-mail: professorwsl@gmail.com

${ }^{2}$ Doutora em Educação para Ciência pela Universidade Estadual Paulista Julio de Mesquita Filho (Unesp/Bauru). Docente da Universidade Estadual do Oeste do Paraná (Unioeste), Grupo de Pesquisa em Educação em Ciências e Biologia - Gecibio, Cascavel, Paraná, Brasil. E-mail: lourdesjustina@gmail.com
} 
DOI: http://dx.doi.org/10.33238/ReBECEM.2019.v.3.n.3.23845

visões e concepções, tendo em vista que essa discussão forma cidadãos que, consequentemente, adotarão ações mais conscientes na transformação social. As universidades funcionam, em geral, com fins distribuídos em eixos fundamentais, quais sejam, o ensino, a pesquisa e a extensão. Esses três eixos, como descrito na Constituição Federal de 1988, não podem ser dissociáveis, ou seja, não podem atuar com a falta de um ou sozinhos (BRASIL, 1988).

Entretanto, por vezes, e até mesmo na maioria das vezes, esse "tripé" não está devidamente equiparado, pois o que realmente ocorre é a dissociação dos eixos de acordo com as ênfases dadas a cada nível de ensino, como no caso da graduação, em que o foco costuma se manter no ensino, enquanto na pós-graduação costuma predominar a pesquisa (MOITA; ANDRADE, 2009). Segundo os referidos autores, o ensino, a pesquisa e a extensão devem ocorrer priorizando o contato com a comunidade e as necessidades nela observadas. Assim, a indissociabilidade desses três elementos garante a produção de conhecimento científico efetivo e, consequentemente, a intervenção na sociedade para a sua transformação, acrescentando, ampliando e disseminando visões sobre a temática em estudo.

As atividades de pesquisa e extensão são essenciais na formação do indivíduo, pois também garantem a produção de conhecimento e, por isso, deveriam ser ofertadas à maioria dos estudantes, propiciando condições para que todos pudessem participar e, assim, construir um cidadão consciente (GOULART, 2004). Em termos legais, a Lei de Diretrizes e Bases da Educação Nacional de 1996 (BRASIL, 1996) garante que as atividades universitárias de pesquisa e extensão podem receber apoio financeiro por parte do governo, incluindo bolsas de estudos e, além disso, nos últimos anos, estuda-se a curricularização da extensão, demonstrando então a importância dessas atividades.

É nesse momento que visualizamos a importância de atividades para atuação na sociedade sobre sexualidade, uma vez que a temática é debatida em todos os espaços sociais (escolas, igrejas, ambientes comerciais, locais públicos, festas, etc.), embora esses debates apareçam com enfoques e abordagens distintas e contraditórias a depender do local onde ocorrem. Diante disso, embora sempre se iniciem no senso comum, é necessário que essas discussões formais não permaneçam nesse estágio, mas, sim, que apresentem determinadas características de criticidade enraizadas nas diversas atividades da universidade, que, direta ou indiretamente, introduz, na sociedade, os conhecimentos produzidos e acumulados na academia. 
DOI: http://dx.doi.org/10.33238/ReBECEM.2019.v.3.n.3.23845

A sexualidade, ao menos em determinados aspectos, não é de simples abordagem na sociedade, seja por vergonha, medo ou até mesmo preconceito. Apesar da presença desses empecilhos, discussões sobre essa temática ocorrem impulsionadas por lutas de movimentos sociais e avanços científicos e tecnológicos, em todos os âmbitos, mostrando que a sexualidade não é algo pessoal e particular, mas, sim, social e político. Ela não é algo dado e pronto, mas, sim, construída de forma plural e cultural, expressando suas verdades, seus conceitos, suas possibilidades. A sexualidade é algo muito mais abrangente que os aspectos relacionados apenas ao corpo biológico, embora este também seja fundamental (LOURO, 2000).

Compreendemos, portanto, a sexualidade como aspectos relacionados ao corpo e ao prazer construídos de forma individual e, simultaneamente, de forma coletiva, todavia que não se restringe a padrões fixos e com limites definidos. Dessa forma, não é algo que permanece estagnado, senão que subsiste de forma contínua, dinâmica e, por vezes, até cíclica. Ao delimitarmos padrões de toda a pluralidade sexual, como ao apontarmos algumas nomenclaturas, visualizamos a exclusão de outras possibilidades e sobreposições que também são legítimas. Entretanto, reconhecemos a importância dessas delimitações, em especial, quando consideramos os aspectos legais e de direitos.

Pretendemos, com este trabalho, tecer algumas relações e fomentar reflexões sobre o trabalho extensionista da universidade investigada, em especial acerca dessa temática da sexualidade. A exposição dos dados e análises está voltada para a amplitude das atividades quanto às suas tipologias, áreas de conhecimento em que foram ofertadas, públicos-alvo e objetivos visados.

\section{$2 \mathrm{O}$ percurso metodológico}

A pesquisa possui caráter qualitativo com o tratamento dos dados obtidos, permeado pela significativa observação e reflexão do pesquisador como parte do processo de produção de conhecimento (FLICK, 2009). Desencadeamos uma análise sobre atividades de extensão a partir da Análise do Conteúdo, de Bardin (2016), análise que, entre a descrição e a interpretação, é designada como:

\footnotetext{
Um conjunto de técnicas de análise das comunicações visando obter, por procedimentos sistemáticos e objetivos de descrição do conteúdo das mensagens, indicadores (quantitativos ou não) que permitam a inferência de conhecimentos relativos às condições de produção/recepção (variáveis inferidas) dessas mensagens (BARDIN, 2016, p. 48).
} 
DOI: http://dx.doi.org/10.33238/ReBECEM.2019.v.3.n.3.23845

Para tal, levantamos, junto à Pró Reitoria de Extensão da universidade estudada, dentre as suas atividades de extensão, quais eram as que apresentavam a temática da sexualidade como central. Por meio do sistema de consulta às atividades de extensão disponibilizado, via sistema interno on-line, acessamos o mecanismo de busca mediante o uso do termo "sex".

No portal consultado, a atividade mais antiga da temática ocorreu em 2003. Dessa forma, em nosso estudo consideramos todas as atividades lançadas no sistema (exceto as que constavam em situação "atividade cancelada" ou "arquivado protocolo geral cancelado") até dezembro de 2018, totalizando aproximadamente 15 anos. Obtivemos um montante de 73 atividades e, delas, 2 não estavam relacionadas à sexualidade e 4 em situação de cancelamento. Então, como já exposto, restaram 67 atividades a serem analisadas.

Uma das atividades aparece por 14 vezes, com alteração apenas quanto aos locais de desenvolvimento. Assim, quando percebemos que essas diferenças não seriam significativas dentro de nossas unidades temáticas de análise, optamos por considerá-la uma única atividade, reduzindo então a nossa amostra a 54 atividades, que foram identificadas com a letra "A" seguida de número cardinal (A1-A54).

Embora o trabalho investigativo seja mais amplo, neste artigo as unidades temáticas apresentadas e analisadas são as tipologias das atividades, o ano de início, as áreas de saber, os públicos-alvo e os objetivos, os quais, em sua maioria, foram obtidos como dados diretos, sem a necessidade de descompactação ou fragmentação textual, com exceção dos objetivos e de algumas informações quanto ao público-alvo, que foram obtidas pelos resumos das propostas das atividades. Assim os dados observados, foram categorizados de acordo com as unidades de registro que foram sendo constituídas.

Quadro 1: Unidades temáticas e categorias analisadas nas atividades extensionistas

\begin{tabular}{|c|c|c|}
\hline Unidades temáticas & Categorias & Descrição \\
\hline \multirow{4}{*}{ Tipo de atividade } & Projeto & Possui cunho educativo, é contínuo e processual. \\
\hline & Evento & Apresentação pública ou específica de saberes. \\
\hline & Curso & Cunho educativo para comunidade com mín. 8h. \\
\hline & Prestação de serviço & Para públicos específicos para execução de ações. \\
\hline Ano de início & De 2003 a 2018 & \\
\hline \multirow{5}{*}{ Áreas de saber } & Ciências da Saúde & \multirow{5}{*}{$\begin{array}{l}\text { Ainda se subdividiam em áreas temáticas como } \\
\text { saúde, educação, cultura, comunicação, direitos } \\
\text { humanos e justiça. }\end{array}$} \\
\hline & Ciências Humanas & \\
\hline & $\begin{array}{l}\text { Linguística, Letras e } \\
\text { Artes }\end{array}$ & \\
\hline & $\begin{array}{ll}\text { Ciências } & \text { Sociais } \\
\text { Aplicadas } & \end{array}$ & \\
\hline & Ciências Biológicas & \\
\hline Públicos-alvo & \multicolumn{2}{|l|}{ Acadêmicos } \\
\hline
\end{tabular}


DOI: http://dx.doi.org/10.33238/ReBECEM.2019.v.3.n.3.23845

\begin{tabular}{|l|l|}
\hline \multirow{5}{*}{} & Professores \\
\cline { 2 - 3 } & Participantes de grupos de pesquisa \\
\cline { 2 - 3 } & Discentes \\
\cline { 2 - 3 } Objetivos & Pomunidade escolar \\
\cline { 2 - 3 } & Profissionais de Instituições Socioeducativas \\
\cline { 2 - 2 } & Participantes de Instituições Socioeducativas \\
\cline { 2 - 2 } & Participantes de movimentos sociais \\
\cline { 2 - 2 } & População em geral \\
\cline { 2 - 2 } & Profissionais da saúde \\
\hline & Sensibilização/Reflexão \\
\cline { 2 - 2 } & Capacitação/Formação \\
\cline { 2 - 2 } & Ampliação da visibilidade da temática \\
\cline { 2 - 2 } & Educar para a sexualidade \\
\hline
\end{tabular}

Fonte: Dados da pesquisa (2018)

No Quadro 1 demonstramos de forma geral, como as unidades temáticas e categorias foram organizadas neste trabalho. As 4 tipologias de atividade (projeto, evento, curso, prestação de serviço) constantes na pesquisa são brevemente descritas e as áreas de saber são subdividas em áreas temáticas que também foram apresentadas no quadro. O ano de início compreende toda a amostra de nosso trabalho, de 2003 a 2018. Quanto aos públicos-alvo e os objetivos, as categorias apresentadas foram todas emergentes de nossas atividades extensionistas, as quais procuramos organizá-las de acordo com aproximações e similaridades.

\section{A sexualidade nas atividades de extensão}

$\mathrm{Na}$ sequência apresentamos os resultados referentes às (1) tipologias das atividades, (2) ano de início, (3) áreas de saber, (4) públicos-alvo e (5) objetivos. Pretendemos, assim, facilitar a leitura e organizar a apresentação de maneira sistematizada a fim de facilitar a compreensão dos dados, das interpretações e das inferências.

\subsection{Os tipos de atividades}

Nesta unidade temática evidenciamos os tipos de atividade analisadas, conforme apresentado no Quadro 2. Observamos uma predominância, em quantidade, dos projetos e dos cursos oferecidos como atividades de extensão. Juntos, eles correspondem a 78\% do total das atividades. 
DOI: http://dx.doi.org/10.33238/ReBECEM.2019.v.3.n.3.23845

Quadro 2: Tipos de atividades desenvolvidas

\begin{tabular}{|l|c|c|}
\hline \multicolumn{1}{|c|}{$\begin{array}{c}\text { Tipo de } \\
\text { atividade }\end{array}$} & Atividades de extensão & Quantidade \\
\hline Projeto & $\begin{array}{c}\mathrm{A} 4, \mathrm{~A} 9, \mathrm{~A} 10, \mathrm{~A} 12, \mathrm{~A} 13, \mathrm{~A} 15, \mathrm{~A} 16, \mathrm{~A} 19, \mathrm{~A} 20, \mathrm{~A} 21, \mathrm{~A} 23, \mathrm{~A} 27, \mathrm{~A} 28, \\
\mathrm{~A} 29, \mathrm{~A} 30, \mathrm{~A} 39, \mathrm{~A} 40, \mathrm{~A} 42, \mathrm{~A} 45, \mathrm{~A} 46, \mathrm{~A} 50, \mathrm{~A} 52, \mathrm{~A} 53, \mathrm{~A} 54\end{array}$ & 24 \\
\hline Curso & $\mathrm{A} 1, \mathrm{~A} 2, \mathrm{~A} 3, \mathrm{~A} 5, \mathrm{~A} 6, \mathrm{~A} 8, \mathrm{~A} 14, \mathrm{~A} 18, \mathrm{~A} 22, \mathrm{~A} 24, \mathrm{~A} 26, \mathrm{~A} 32, \mathrm{~A} 33$, & 18 \\
\hline Evento & $\mathrm{A} 34, \mathrm{~A} 36, \mathrm{~A} 40, \mathrm{~A} 43, \mathrm{~A} 51$ & 11 \\
\hline $\begin{array}{l}\text { Prestação de } \\
\text { serviço }\end{array}$ & $\mathrm{A} 46$ & 1 \\
\hline
\end{tabular}

Fonte: Dados da pesquisa (2018)

Os projetos, por serem atividades consideradas contínuas processuais, foram tomados por nós como de maior explanação dos temas a serem discutidos, pois se debruçam sobre eles por um maior período. Consideramos que os projetos possuem uma efetiva significância a longo prazo, em especial para os seus colaboradores, que, em sua maioria, se encontram no meio universitário. Os cursos podem apresentar um resultado mais satisfatório quando abordam temas de interesse da comunidade, sendo o próprio participante, nesse caso, o sujeito central de conhecimento.

Não descartamos a efetiva importância de ambos, projetos e cursos, e muito menos dos projetos em relação à comunidade. Ocorre, entretanto, por serem os projetos uma atividade de longa duração, requerem maior contato com a comunidade e sua participação, uma vez que ocorrem em diferentes momentos e encontros, demandando, dos que desejam participar, uma disponibilidade que muitas vezes não possuem.

Quanto aos eventos, das 11 atividades analisadas, 7 (A11, A17, A25, A31, A37, A42, A50) foram edições de uma mostra de cinema, deixando em defasagem a existência de seminários, congressos, e demais eventos, nos quais poderiam ser compartilhados diferentes trabalhos e estudos científicos e que promovam a ampliação dos debates sobre a sexualidade.

Dessa forma, dentro das atividades de extensão da universidade pesquisada, eventos que envolvam a temática sexualidade não possuem uma ampla ocorrência, sendo esta oferta uma das necessidades. A organização de mais eventos acerca da temática, uma vez que a atividade 'evento' é geralmente de caráter público, e possibilita a participação de indivíduos de diferentes setores da sociedade. Evento pode ser considerado o tipo de atividade que abrange uma maior parcela social, possuindo uma função de, ao menos, disseminar essas temáticas, que, segundo Foucault (2017), por vezes é silenciada, negada e expulsa das conversas e das discussões.

Apenas uma atividade, a A46, por se tratar de uma intervenção pedagógica em turma de formação de professores de nível médio, é classificada como 'prestação de 


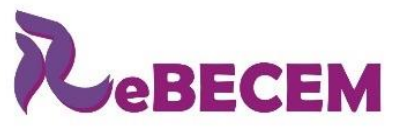

DOI: http://dx.doi.org/10.33238/ReBECEM.2019.v.3.n.3.23845
Revista Brasileira de Educação em

Ciências e Educação Matemática

ISSN 2594-9179

serviço', pois ocorre dentro das atividades profissionais de seu público-alvo e visando o seu respectivo ambiente de atuação. Ao pensar que as 'prestações de serviço' demandam mais aplicabilidade social dos conteúdos estudados, pois possuem um viés de conhecimento voltado para a atuação, sugerimos também que alguns 'projetos' possam ser ampliados para que envolvam também a 'prestação de serviço', uma vez que talvez já possam até mesmo possuir tal objetivo. Destacamos, assim, que equilibrar as diferentes atividades desenvolvidas pode aumentar, em termos quantitativos, 'eventos' e 'prestações de serviço' sobre sexualidade, para que seja debatida no meio social, acadêmico e em outros espaços. Assim, promoveríamos a mediação do saber a pessoas que possam vir a ser, posteriormente, mediadoras de conhecimentos e informações.

\subsection{Ano de início}

Como já expusemos, o sistema de consulta de atividades de extensão nos forneceu dados a partir de 2003, e nas datas de início e término fornecidas considera-se todo o período de trâmite burocrático pelo qual passam as atividades de extensão, não significando que determinada atividade permaneceu ativa em campo todo o período lançado. Assim, optamos por verificar quais foram os anos de início de desenvolvimento das atividades procurando realizar apontamentos históricos sobre alguns dos momentos de desenvolvimento delas.

Ao visualizarmos o Quadro 3 notamos um aumento significativo nas atividades de extensão que envolvem a sexualidade a partir de 2011. Todavia tal número vem a ser reduzido em 2015, e torna a aumentar em 2017, mas de forma tímida. Notamos que ocorreu uma diminuição expressiva de 2014 a 2015, nos fazendo refletir sobre o nosso contexto histórico brasileiro.

Em 2014 se caminhava para a finalização da construção o Plano Nacional de Educação (PNE), e os termos "gênero" e "orientação sexual" eram alvo de grande debate midiático e político, questionando se poderiam ou não estar presentes em tal documento. Diante disso, diferentes setores sociais começaram a se manifestar sobre as possibilidades ou não de tal inserção, ocasionando embates entre diferentes grupos e possíveis alterações nos planos estaduais e municipais. Por fim, os termos não apareceram no PNE, porém, esse plano expõe, em uma de suas diretrizes, a “[...] promoção dos princípios do respeito aos direitos humanos, à diversidade e à sustentabilidade socioambiental" (BRASIL, 
DOI: http://dx.doi.org/10.33238/ReBECEM.2019.v.3.n.3.23845

2014, grifo nosso), o que nos permite, em sala de aula, discutir as diferenças visando o respeito ao próximo.

Quadro 3: Anos de início das atividades

\begin{tabular}{|c|c|l|}
\hline Ano de início & Quantidade & \multicolumn{1}{c|}{ Atividades de extensão } \\
\hline 2003 & 4 & $\mathrm{~A} 1, \mathrm{~A} 2, \mathrm{~A} 3, \mathrm{~A} 4$ \\
\hline 2004 & 2 & $\mathrm{~A} 5, \mathrm{~A} 6$ \\
\hline 2005 & 1 & $\mathrm{~A} 7$ \\
\hline 2006 & 0 & \\
\hline 2007 & 1 & $\mathrm{~A} 8$ \\
\hline 2008 & 1 & $\mathrm{~A} 9$ \\
\hline 2009 & 1 & $\mathrm{~A} 10$ \\
\hline 2010 & 2 & $\mathrm{~A} 11, \mathrm{~A} 12$ \\
\hline 2011 & 4 & $\mathrm{~A} 13, \mathrm{~A} 14, \mathrm{~A} 15, \mathrm{~A} 16$ \\
\hline 2012 & 6 & $\mathrm{~A} 17, \mathrm{~A} 18, \mathrm{~A} 19, \mathrm{~A} 20, \mathrm{~A} 21$ \\
\hline 2013 & 8 & $\mathrm{~A} 22, \mathrm{~A} 23, \mathrm{~A} 24, \mathrm{~A} 25, \mathrm{~A} 26, \mathrm{~A} 27, \mathrm{~A} 28, \mathrm{~A} 29$ \\
\hline 2014 & 10 & $\mathrm{~A} 30, \mathrm{~A} 31, \mathrm{~A} 32, \mathrm{~A} 33, \mathrm{~A} 34, \mathrm{~A} 35, \mathrm{~A} 36, \mathrm{~A} 37, \mathrm{~A} 38, \mathrm{~A} 39$ \\
\hline 2015 & 2 & $\mathrm{~A} 40, \mathrm{~A} 41$ \\
\hline 2016 & 2 & A42, A43 \\
\hline 2017 & 4 & A44, A45, A46, A47 \\
\hline 2018 & 7 & A48, A49, A50, A51, A52, A53, A54 \\
\hline
\end{tabular}

Fonte: Dados da pesquisa (2018)

No mesmo período foi iniciado um forte discurso sobre uma tal "ideologia de gênero", ideologia que, segundo Reis e Eggert (2017), não passa de uma falácia e falta de compreensão do que realmente se refere às discussões de gênero.

Criou-se uma falácia apelidada de "ideologia de gênero", que induziria à destruição da família "tradicional", à legalização da pedofilia, ao fím da "ordem natural" e das relações entre os gêneros, e que nega a existência da discriminação e violência contra mulheres e pessoas LGBT comprovadas com dados oficiais e estudos científicos. Utilizou-se de desonestidade intelectual, formulando argumentos sem fundamentos científicos e replicando-os nas mídias sociais para serem engolidos e regurgitados pelos fiéis acríticos que os aceitam como verdades inquestionáveis. Utilizou-se também de uma espécie de terrorismo moral, atribuindo o status de demônio às pessoas favoráveis ao respeito à igualdade de gênero e diversidade sexual na educação, além de intimidar profissionais de educação com notificações extrajudiciais com ameaça de processo contra quem ousasse abordar esses assuntos na sala de aula. Criou-se um movimento para "apagar" o assunto gênero do currículo escolar (REIS; EGGERT, 2017, p. 20).

Mediante todas as repercussões, podemos talvez compreender os motivos de ocorrer uma minimização na quantidade de atividades nessa época de 2014 e 2015, tendo em vista que as atividades de extensão são realizadas por pessoas e estas, colocam sua vida pessoal, profissional e até mesmo o nome de sua universidade a mercê de críticas e de preconceitos.

Apesar de termos, portanto, um certo silenciamento ao trabalhar com sexualidade e consequentemente a diversidade presente em nossas vivências, algo que merece ser destacado quando trabalhamos com a diversidade sexual em diferentes contextos 


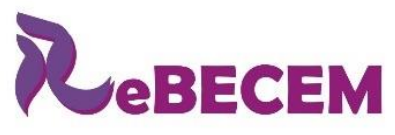

DOI: http://dx.doi.org/10.33238/ReBECEM.2019.v.3.n.3.23845
Revista Brasileira de Educação em

Ciências e Educação Matemática

ISSN 2594-9179

educacionais é a cautela que deve ser considerada, para não ficarmos novamente presos aos padrões binários, como citar apenas a homossexualidade, não explicitando outras formas de sexualidade, como as diferentes orientações sexuais e identidades de gênero. Diante disso, também podemos discutir a heteronormatividade e o preconceito àquilo que "foge do normal", bem como as diferentes masculinidades e feminilidades vivenciadas.

Herneck, Ferraço e Teixeira (2017) apontam que, ao discutir com educandos os padrões existentes na sociedade, também se faz necessário refletir sobre as violências que ocorrem em diferentes lugares, em especial dentro das casas dos próprios discentes, ao serem regrados e inibidos de se manifestarem sexualmente como queiram, sendo que essa repreensão pode ser propagada dentro de ambientes escolares com discursos e ações discriminatórias tanto pelo reprimido quanto para reprimir o outro.

Nesse panorama, Pessoa et al., (2017) observaram, em escolas, a falta de recursos, o conservadorismo, a discriminação e, consequentemente, a individualização, o que promove uma possível vulnerabilidade de indivíduos marginalizados, que são, no caso da pesquisa dos referidos autores, as vítimas de abuso sexual. Diante de tais situações escolares, os autores refletem se o ambiente escolar está favorecendo ou vulnerabilizando as vítimas em processo de resiliência.

Nesse sentido, discutir amplamente a discriminação e o bullying realizado com pessoas de diferentes sexualidades pode expor fatos que ultrapassam as barreiras de um “comum" preconceito entre colegas de escola, que podem desencadear diferentes reações e consequências (ESPEJO, 2017). Para tal, faz-se necessário que essas discussões sejam aprimoradas, expandidas, sejam elas dentro do ambiente escolar/universitário ou para qualquer outro público. Embora as atividades de extensão tenham diminuído a sua quantidade após as intempéries citadas, percebemos que elas voltaram novamente a aumentar em 2017, denotando uma demanda represada.

Embora a diminuição da recorrência de termos em documentos oficiais, e consequentemente um movimento indireto (ou direto e escancarado) que tenta inibir o trabalho com sexualidade nos ambientes escolares, a universidade, por meio das atividades extensionistas, pode contribuir para um respaldo científico, acadêmico e social para que possamos discutir em diferentes âmbitos e setores aspectos de violências, discriminação, bullying, autonomias sexuais, atitudes docentes etc., lutando assim, para disseminação de saberes científicos e contra a propagação de notícias falsas e sensacionalistas. 


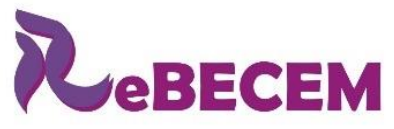

\section{3 Áreas de desenvolvimento das atividades}

Elencamos, no Quadro 4, a seguir, as grandes áreas para as quais foram destinadas as atividades e suas respectivas áreas temáticas descritas, que poderiam contemplar até duas. Sendo assim, pelo fato de as atividades constarem área temática principal e secundária, enquadramos uma mesma atividade em mais que uma categoria. Dessa forma visualizamos uma vantagem quantitativa na grande área das 'Ciências Humanas' (30 atividades), em especial com a área temática da 'educação' (29 atividades), que é a única área presente em todas as outras grandes áreas, assim fica destacada a sua notoriedade, uma vez que das 54 atividades, 46 são pertencentes à área temática da educação.

\begin{tabular}{|c|c|c|c|c|}
\hline \multirow[b]{2}{*}{ Grande área } & \multirow[b]{2}{*}{ Área temática } & \multirow[b]{2}{*}{ Atividades } & \multicolumn{2}{|c|}{ Quantidade } \\
\hline & & & $\begin{array}{c}\text { Área } \\
\text { T. }\end{array}$ & $\begin{array}{c}\text { Grande } \\
\text { Área }\end{array}$ \\
\hline \multirow{2}{*}{$\begin{array}{l}\text { Ciências da } \\
\text { Saúde }\end{array}$} & Saúde & $\begin{array}{c}\mathrm{A} 1, \mathrm{~A} 3, \mathrm{~A} 9, \mathrm{~A} 10, \mathrm{~A} 13, \mathrm{~A} 35, \mathrm{~A} 36, \mathrm{~A} 41, \\
\mathrm{~A} 48, \mathrm{~A} 54\end{array}$ & 10 & \multirow{2}{*}{10} \\
\hline & Educação & $\begin{array}{c}\mathrm{A} 1, \mathrm{~A} 3, \mathrm{~A} 10, \mathrm{~A} 13, \mathrm{~A} 35, \mathrm{~A} 36, \mathrm{~A} 41, \mathrm{~A} 48, \\
\text { A54 }\end{array}$ & 9 & \\
\hline \multirow{4}{*}{$\begin{array}{l}\text { Ciências } \\
\text { Humanas }\end{array}$} & Educação & $\begin{array}{c}\text { A2, A4, A5, A6, A7, A8, A12, A14, A15, } \\
\text { A16, A18, A19, A20, A21, A22, A24, A26, } \\
\text { A28, A29, A32, A33, A34, A39, A43, A44, } \\
\text { A45, A46, A51, A53 }\end{array}$ & 29 & \multirow{4}{*}{30} \\
\hline & Cultura & A12, A20, A21, A39 & 4 & \\
\hline & Comunicação & $\mathrm{A} 28, \mathrm{~A} 40$ & 2 & \\
\hline & $\begin{array}{l}\text { Direitos } \\
\text { Humanos e } \\
\text { Justiça }\end{array}$ & A19 & 1 & \\
\hline \multirow{4}{*}{$\begin{array}{l}\text { Linguística, } \\
\text { Letras e Artes }\end{array}$} & $\begin{array}{c}\text { Direitos } \\
\text { Humanos e } \\
\text { Justiça }\end{array}$ & $\mathrm{A} 17, \mathrm{~A} 25, \mathrm{~A} 27, \mathrm{~A} 31, \mathrm{~A} 37, \mathrm{~A} 42, \mathrm{~A} 50$ & 7 & \multirow{4}{*}{8} \\
\hline & Educação & $\mathrm{A} 17, \mathrm{~A} 25, \mathrm{~A} 27, \mathrm{~A} 31, \mathrm{~A} 37$ & 5 & \\
\hline & Comunicação & $\mathrm{A} 42, \mathrm{~A} 50$ & 2 & \\
\hline & Cultura & A11 & 1 & \\
\hline \multirow[t]{2}{*}{$\begin{array}{l}\text { Ciências } \\
\text { Sociais } \\
\text { Aplicadas }\end{array}$} & $\begin{array}{c}\text { Direitos } \\
\text { Humanos e } \\
\text { Justiça }\end{array}$ & A23, A47, A49, A52 & 4 & \multirow[t]{2}{*}{4} \\
\hline & Educação & A23 & 1 & \\
\hline \multirow{2}{*}{$\begin{array}{c}\text { Ciências } \\
\text { Biológicas }\end{array}$} & Educação & $\mathrm{A} 30, \mathrm{~A} 38$ & 2 & \multirow{2}{*}{2} \\
\hline & Saúde & A30, A38 & 2 & \\
\hline
\end{tabular}

Fonte: Dados da pesquisa (2018)

Para Furlani (2013), é essencial que adicionemos temáticas como a sexualidade em nossos currículos, pois, caso não o façamos, nossos alunos não estarão sendo educados de forma integral e visando uma cidadania coletiva. Ao percebermos essa preocupação da universidade em fornecer subsídio para a sua abordagem no âmbito educacional, além de reconhecermos que o respaldo acadêmico favorece o debate, possibilitamos a 


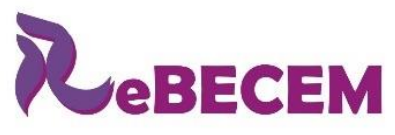

DOI: http://dx.doi.org/10.33238/ReBECEM.2019.v.3.n.3.23845
Revista Brasileira de Educação em

Ciências e Educação Matemática

democratização de saberes que se vinculam nesse meio e podem ser mediados a outros segmentos.

Ouvimos, por vezes, um discurso recorrente de que caberia ao profissional professor da Educação Básica, nas disciplinas de Ciências e/ou Biologia, a competência da Educação Sexual (PEIXOTO; MAIO, 2013). Todavia, além de esses profissionais não se sentirem preparados para abordar todas as vertentes da sexualidade, os PCN construídos no final da década de 1990 (BRASIL, 1997, 1998) já traziam a temática da Orientação Sexual como um tema transversal a ser discutido em todas as disciplinas.

Assim, Peixoto e Maio (2013) ainda corroboram o entendimento de Furlani (2013), de que essa temática deve ser debatida continuamente nas escolas, pois a todo instante os alunos são bombardeados por informações midiáticas, que, por vezes, não são dotadas de respaldos científicos, produzindo, mesmo sem as discussões, sexualidades. Ou seja, sem Educação Sexual nas escolas, a sexualidade é construída de igual forma ou, melhor, de uma diferente forma, uma forma de inibição.

Ao observarmos o Quadro 4, na área das 'Ciências Biológicas' ocorreu uma das menores quantidades de atividades de extensão (A30, A38), contrariando o que ocorre nas outras etapas de ensino (como nos anos finais do Ensino Fundamental e no Ensino Médio). Um dos problemas apontados por Vieira e Matsukura (2017) é o fato de que esses profissionais (professores de Ciências e Biologia), em sua maioria, permanecerem no ensino num modelo biológico-centrado, por vezes, num âmbito apenas da saúde, todavia, como já exposto anteriormente nesse trabalho, eles mesmos reconhecem as suas limitações. Ressaltamos que não descartamos que a Biologia auxilia na compreensão do corpo na Educação Sexual, entretanto não é possível analisar a sexualidade apenas dentro desse aspecto.

A formação de professores carece de um trabalho mais efetivo relacionado à sexualidade, seja ela a formação docente inicial ou a chamada formação docente continuada (HERNECK; FERRAÇO; TEIXEIRA, 2017; VIEIRA; MATSUKURA, 2017; BROL; MARTELLI, 2018), sendo, por vezes, percebidas ações munidas de preconceitos até mesmo pelos educadores (ESPEJO, 2017). Grande parte dos professores, ao completarem a sua formação inicial, não se sentem preparados e habilitados para trabalhar com a temática (embora a considerem importante). Dessa forma, os professores que tendem a trabalhar com sexualidade são apenas os de Ciências e Biologia, restringindo-se aos aspectos biológicos e minimizando os sociais (VIEIRA; MATSUKURA, 2017). 


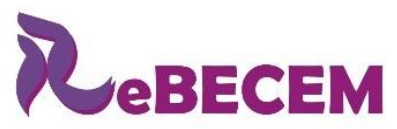

\section{Revista Brasileira de Educação em \\ Ciências e Educação Matemática}

DOI: http://dx.doi.org/10.33238/ReBECEM.2019.v.3.n.3.23845

Percebemos, assim, que as atividades de extensão têm sido trabalhadas em olhares divergentes ao que ocorre nas escolas. Não que isso seja percebido como um problema, mas que os debates estão sendo ampliados para diferentes áreas. Isso pode possibilitar a formação tanto dos acadêmicos ao atuarem nas atividades quanto a de seu público, demonstrando, ainda, as diferentes abrangências que a Educação Sexual necessita explicitar, sejam elas em aspectos sociais, psicológicos ou biológicos.

A temática da sexualidade também está relacionada à área dos direitos humanos (A17, A19, A23, A25, A27, A31, A37, A42, A47, A49, A50, A52) e merece destaque, pois essa área também integra o âmbito de formação do Estado Democrático de Direito brasileiro em um de seus fundamentos, como proposto no artigo $1^{\text {o: }}$ "III - a dignidade da pessoa humana" e no artigo $4^{\text {o: }}$ "II - prevalência dos direitos humanos", da Constituição Federal (BRASIL, 1988, s/p).

Ao nos referirmos à sexualidade como direito humano, observamos que esse tema apresenta ampla potencialidade em abranger os mais variados aspectos e setores de nossa sociedade e humanidade, permeando todas as disciplinas curriculares e áreas de conhecimento dentro do ambiente escolar, já que esse ambiente também é um local de pluralidade cultural e, consequentemente, de visualização de diferentes vivências.

\subsection{Públicos-Alvo}

No Quadro 5 observamos os públicos-alvo a que foram destinadas as atividades de extensão analisadas. Vale ressaltar que a maioria das atividades apresentava vínculo educacional, remetendo a outras etapas de ensino e ao diálogo entre os diferentes níveis formativos.

Quadro 5: Públicos-alvo das atividades

\begin{tabular}{|c|c|c|}
\hline \multicolumn{2}{|l|}{ Público-alvo } & Atividades de extensão \\
\hline \multirow{4}{*}{ Acadêmicos } & Área Educacional & $\begin{array}{l}\text { A2, A5, A7, A14, A17, A25, A31, A37, } \\
\text { A43, A47, A48 }\end{array}$ \\
\hline & Áreas da Saúde & $\mathrm{A} 1, \mathrm{~A} 3, \mathrm{~A} 17, \mathrm{~A} 25, \mathrm{~A} 31, \mathrm{~A} 37$ \\
\hline & Direito & A47 \\
\hline & Em geral & $\mathrm{A} 35, \mathrm{~A} 40, \mathrm{~A} 42, \mathrm{~A} 52$ \\
\hline \multirow{4}{*}{ Professores } & EM e EF (anos finais) & $\begin{array}{l}\text { A2, A5, A7, A18 A22, A30, A40, A42, } \\
\text { A48, A54 }\end{array}$ \\
\hline & EF (anos iniciais) e EI & $\begin{array}{l}\text { A2, A4, A5, A6, A8, A14, A24, A26, A32, } \\
\text { A33, A34, A36, A47 }\end{array}$ \\
\hline & Ensino Superior & $\mathrm{A} 17, \mathrm{~A} 25, \mathrm{~A} 31, \mathrm{~A} 37, \mathrm{~A} 40, \mathrm{~A} 42$ \\
\hline & Educação Especial & A15 \\
\hline \multicolumn{2}{|c|}{ Participantes de grupos de pesquisa } & A15, A16, A39, A53 \\
\hline \multirow{2}{*}{ Discentes } & Adolescentes & $\mathrm{A} 9, \mathrm{~A} 10, \mathrm{~A} 13, \mathrm{~A} 38, \mathrm{~A} 40, \mathrm{~A} 41, \mathrm{~A} 42$ \\
\hline & Educação Especial & A15 \\
\hline
\end{tabular}


DOI: http://dx.doi.org/10.33238/ReBECEM.2019.v.3.n.3.23845

\begin{tabular}{|l|l|}
\hline \multicolumn{1}{|l|}{ Curso de Formação de docentes } & A44, A46, A51 \\
\hline Comunidade escolar & A45 \\
\hline Profissionais de Instituições Socioeducativas & A12, A16, A23, A39, A47, A52 \\
\hline Participantes de Instituições Socioeducativas & A16, A19, A20, A21, A29 \\
\hline Participantes de movimentos sociais & A17, A25, A27, A31, A37, A52 \\
\hline População em geral & A11, A17, A25, A28, A31, A47, A49, A50, \\
\hline Profissionais da saúde & A52 \\
\hline
\end{tabular}

Fonte: Dados da pesquisa (2018)

Alguns públicos não foram precisamente delimitados, o que nos fez recorrer aos resumos para enfatizarmos a quem seriam destinados, como o caso a atividade A30, de que, na opção objetiva, constava apenas "professores" e a A46 apresentava apenas "alunos", no resumo o público foi especificado:

O trabalho será desenvolvido com instrumentalização de um grupo de trabalho vinculado ao Programa de Desenvolvimento Educacional (PDE) do Estado do Paraná, sendo desenvolvido em uma escola pública estadual de Cascavel A30.

Assim, com esses conhecimentos, ter subsídios para desenvolver um Projeto de intervenção pedagógica com alunos e alunas de Formação de Docentes em Nível Médio - A46.

Em sua maioria, os públicos a que se destinam as atividades de extensão são acadêmicos e professores atuantes nos outros níveis de ensino, o que pode ser visualizado como fundamental, tendo em vista que a formação desses indivíduos deve ser voltada para o respeito, em especial, por manterem um contato cotidiano com a diversidade. Asinelli-Luz (2008) nos faz atentar para a importância desse tipo de atividade, por atuar com multiplicadores que disseminarão tais saberes.

Em um recente estudo na cidade de Cascavel-PR, sobre cursos de formação de professores para sexualidade no município, as autoras Brol e Martelli (2018) consideraram que embora escassa a quantidade de cursos de formação docente para sexualidade em um município brasileiro, estes promovem transformações nos posicionamentos dos docentes e, assim, eles conseguem passar a inserir essa temática em suas práticas pedagógicas com maior naturalidade.

Além disso, como Furlani (2013) e Louro (2014) nos relembram, por a escola ser também um local de disciplinamento de corpos, os profissionais que atuam ou atuarão na educação devem possuir uma formação que os qualifique a vivenciar e a administrar situações em sala de aula em que se oportunizem discussões de gênero (CARDOSO; MWOLO, 2017), de violência (PESSOA et al., 2017; MÉNDEZ-TAPIA, 2017), de sexualidade e de Educação Sexual amplamente (HERNECK; FERRAÇO; TEIXEIRA, 2017; VIEIRA; MATSUKURA, 2017). 
DOI: http://dx.doi.org/10.33238/ReBECEM.2019.v.3.n.3.23845

[...] muitas são as áreas e assuntos de que os/as profissionais docentes não possuem os conhecimentos necessários para incluir as diversas temáticas nos planejamentos escolares, como, por exemplo, a Educação Sexual, que, historicamente, tem deixado uma lacuna aberta nos currículos escolares, pois a escola, os/as docentes e os/as gestores/as não sabem, muitas vezes, como lidar e como garantir que ela seja ensinada (PEIXOTO; MAIO, 2013, p. 22).

Um aspecto a ser discutido é o fato de quanto mais novos forem os indivíduos, mais eles são considerados sem sexualidade, seres assexuados, como o caso das crianças (FOUCAULT, 2017). E esse discurso tende a crescer dia após dia, não só no meio social e político que vivenciamos, como nos ambientes escolares. Notamos também que a Educação Infantil é etapa educacional que apresenta escassos documentos, regulamentos e instruções de políticas públicas sobre a sexualidade e a Educação Sexual (FINCO, 2015) - o que também contribui para que a temática não seja abordada em sala de aula.

Denotamos, assim, a importância do contato entre diferentes níveis e etapas de ensino, frisando as suas necessidades, pois, ao mesmo tempo que os docentes do Ensino Fundamental e da Educação Infantil foram os que mais receberam ofertas de atividades extensionistas disponibilizadas pelo Ensino Superior, também foram os docentes dessas etapas de ensino que mais apresentaram resistência quanto a abordar essa temática, tanto por pressão social, como por despreparo decorrente de ausência da formação inicial e continuada dos profissionais da educação (SILVA; SARMENTO; FOSSATTI, 2012).

Todavia, para que possamos abordar sexualidade em sala de aula, e para que não gere possíveis interpretações que venham a deslegitimar tais discussões - de acordo, é claro, com cada faixa etária -, é necessário o envolvimento de toda a comunidade escolar, como no caso dos pais, os quais devem também compreender a importância de tais temas na formação individual e coletiva de seus filhos (RIBEIRO, 2011; JAEGER; JACQUES, 2017).

Ademais, observamos que são também poucas as atividades destinadas ao público docente do Ensino Superior. As únicas atividades voltadas para esse público são as edições das Mostras de Cinema/Filmes (A17, A25, A31, A37, A40, A42, A50), que são também voltadas, em geral, para toda a população que possui interesse na temática. Assim sendo, nós nos questionamos sobre como seriam, caso fossem promovidas, as atividades de formação dos docentes que atuam na formação de professores da Educação Básica. Uma possibilidade formativa, mas também escassa, de grupos de estudos vinculados aos grupos de pesquisa, os quais fazem parte os docentes do Ensino Superior, promovendo as discussões da temática com esse público. 
DOI: http://dx.doi.org/10.33238/ReBECEM.2019.v.3.n.3.23845

Destacamos também o trabalho com adolescentes, que pode ser visualizado enquanto discentes, e participantes de instituições socioeducativas. Viera e Matsukura (2017) apresentam a importância da Educação Sexual pautada em aspectos biopsicossociais para adolescentes, em razão de que esses são descritos como um grupo em risco e vulnerável ao sexo, embora apontem que exista uma prevalência de conteúdos biologizantes. As autoras recomendam que a saúde dos adolescentes deve ser trabalhada em conjunto com os setores do âmbito governamental de "saúde" e de "educação", e para isso também se faz necessária a capacitação dos professores para que compreendam a diversidade de sexualidades com a qual trabalham e que permitam a autonomia e direito de escolhas sobre seu corpo por parte dos alunos.

Diante disso, visualizamos também a presença de atividades voltadas a segmentos sociais vulneráveis, como instituições socioeducativas e Unidades Básica de Saúde, tanto para os respectivos profissionais, quanto para os seus participantes, o que demonstra certa preocupação de discussões sobre sexualidade para os públicos de maior vulnerabilidade social. Talvez esse também seja um caminho de acolhimento para esses indivíduos, tendo em vista que Pessoa et al., (2017) refletem se o ambiente escolar não estaria auxiliando na vulnerabilização desses mesmos indivíduos.

\subsection{Os objetivos}

Nos resumos das atividades de extensão universitária pesquisadas encontramos diversas informações sobre como o trabalho foi desenvolvido, inclusive os seus objetivos. Procuramos aproximar os objetivos trazidos pelas atividades, de forma que ficassem agrupados em apenas uma categoria, todavia algumas atividades apresentaram objetivos sem diferenças significativas ou trazidos como secundários. Assim, algumas atividades ainda permaneceram em mais de uma categoria.

Durante a elaboração do Quadro 6 observamos uma relação das atividades no sentido da capacitação e da sensibilização dos participantes. Dessa forma, delimitamos que, quando a atividade possuía um objetivo primário voltado para o trabalho de formação de multiplicadores, desenvolvendo estratégias de trabalho, metodologias e ações, ele pertenceria à categoria 'Capacitação/Formação' e, quando o foco era centrado mais nas compreensões pessoais/sociais da sexualidade, conceitos atitudinais e estudos teóricos, foi enquadrado na categoria 'Sensibilização/Reflexão'. 
DOI: http://dx.doi.org/10.33238/ReBECEM.2019.v.3.n.3.23845

Exemplificando ainda, quando centrado no "como trabalhar", categoria de 'Capacitação/Formação', e quando centrado no "por que trabalhar", categoria de 'Sensibilização/Reflexão'. Todavia, ressaltamos que tais categorias apenas foram organizadas com um foco sistemático, pois reconhecemos que realizar a sensibilização e possibilitar reflexões também podem fazer parte do processo de formação profissional dos indivíduos.

\begin{tabular}{|c|c|c|}
\hline \multicolumn{3}{|c|}{ Quadro 6: Objetivos das atividades } \\
\hline Objetivo & Atividades & Quantidade \\
\hline Sensibilização/Reflexão & $\begin{array}{c}\mathrm{A} 1, \mathrm{~A} 2, \mathrm{~A} 3, \mathrm{~A} 4, \mathrm{~A} 5, \mathrm{~A} 7, \mathrm{~A} 14, \mathrm{~A} 16, \mathrm{~A} 18, \mathrm{~A} 22, \mathrm{~A} 24, \\
\mathrm{~A} 26, \mathrm{~A} 32, \mathrm{~A} 33, \mathrm{~A} 34, \mathrm{~A} 39, \mathrm{~A} 43, \mathrm{~A} 44, \mathrm{~A} 46, \mathrm{~A} 47, \mathrm{~A} 48, \\
\mathrm{~A} 49, \mathrm{~A} 53\end{array}$ & 23 \\
\hline Capacitação/Formação & $\begin{array}{c}\mathrm{A} 1, \mathrm{~A} 3, \mathrm{~A} 6, \mathrm{~A} 8, \mathrm{~A} 12, \mathrm{~A} 14, \mathrm{~A} 22, \mathrm{~A} 23, \mathrm{~A} 24, \mathrm{~A} 26, \mathrm{~A} 30, \\
\mathrm{~A} 32, \mathrm{~A} 33, \mathrm{~A} 34, \mathrm{~A} 36, \mathrm{~A} 47, \mathrm{~A} 48, \mathrm{~A} 51, \mathrm{~A} 52\end{array}$ & 19 \\
\hline $\begin{array}{l}\text { Ampliação da visibilidade da } \\
\text { temática }\end{array}$ & $\begin{array}{c}\mathrm{A} 11, \mathrm{~A} 17, \mathrm{~A} 25, \mathrm{~A} 27, \mathrm{~A} 28, \mathrm{~A} 31, \mathrm{~A} 37, \mathrm{~A} 40, \mathrm{~A} 42, \mathrm{~A} 45, \\
\mathrm{~A} 49, \mathrm{~A} 50, \mathrm{~A} 52\end{array}$ & 13 \\
\hline Educar para a sexualidade & $\begin{array}{c}\mathrm{A} 9, \mathrm{~A} 10, \mathrm{~A} 13, \mathrm{~A} 19, \mathrm{~A} 20, \mathrm{~A} 21, \mathrm{~A} 29, \mathrm{~A} 35, \mathrm{~A} 38, \mathrm{~A} 41, \\
\text { A54 }\end{array}$ & 11 \\
\hline Não apresenta & A15 & 1 \\
\hline
\end{tabular}

Fonte: Dados da pesquisa (2018)

De forma geral, as duas primeiras categorias foram centradas em professores e, por reconhecermos tal ligação entre as categorias, consideramos que discutir a sexualidade é necessário em todos os segmentos sociais, em especial no dos profissionais da educação, para que se lhes permita refletirem sobre as suas atitudes e posturas a serem tomadas diante das mais diferentes situações vivenciadas, sendo essencial a discussão dessa temática ainda em sua formação docente inicial.

\begin{abstract}
Quando se fala sobre discutir acerca da sexualidade quer se dizer que devem ser implantadas, nos currículos das licenciaturas, disciplinas que trabalhem sobre sexualidade e diversidade sexual, com abordagens práticas e pedagógicas em sala de aula, visando preparar os/as profissionais da educação para saberem lidar com as situações sobre as manifestações sexuais e dúvidas dos/as alunos/as (PINTO; MAIO, 2017, p. 13).
\end{abstract}

Herneck, Ferraço e Teixeira (2017) corroboram essa afirmação da citação e reforçam a inserção de cursos associados aos aspectos sociais aos professores, tanto na formação inicial quanto continuada. Dessa forma se retiraria a visão escolar da sexualidade com um único viés biologizante. Simultaneamente, a interdisciplinaridade, ao se abordar tal temática nas escolas com certa transversalidade, contribuiria para que docentes de diferentes áreas pudessem expor às alunas e aos alunos e discutir com elas/eles as vertentes científicas de cada área que estejam associadas à sexualidade, contribuindo com uma formação mais abrangente de adolescentes (VIEIRA; MATSUKURA, 2017). 
DOI: http://dx.doi.org/10.33238/ReBECEM.2019.v.3.n.3.23845

Refletimos ainda que, em nossos resultados, a categoria de

'Sensibilização/Reflexão' foi mais incidente que a de capacitação, o que nos instiga a pensar que, de fato, o profissional também precisa reconhecer os seus limites, repensar atitudes e posturas e estar aberto à busca de novas alternativas a fim de possibilitar o desenvolvimento e a autonomia da sexualidade das pessoas com que mantém o contato cotidiano, conforme podemos observar:

[...] visa oferecer, aos educadores, elementos para uma reflexão sobre o tema sexualidade, haja vista que hoje ele se faz presente nos parâmetros curriculares como tema transversal. [...] Busca ainda entender por que, neste momento, a escola é chamada para tratar de assuntos que até então eram um problema apenas familiar - A2.

[...] tem como objetivo qualificar os profissionais da educação no estudo, na discussão e na reflexão sobre gênero e etnia, homofobia, sexismo, diversidade e orientação sexual. Neste aspecto, busca aprofundar a discussão sobre o tema, indo além das questões aparentes. Assim, objetiva compreender as contradições inerentes aos temas e desvelar as razões econômicas e culturais que fortalecem as diversas formas de preconceitos sociais - A18.

O objetivo é problematizar questões relacionadas à sexualidade e educação a partir da análise de discurso e da noção de imaginário - A43.

A autonomia sexual que defendemos, por parte de docentes e estudantes, perpassa questões sociais, psicológicas e biológicas, e tudo isso remete aos posicionamentos do indivíduo e ao seu direito de fazer o que melhor desejar com o seu corpo e os seus prazeres (VIEIRA; MATSUKURA, 2017). É uma autonomia que também pode encaminhar, orientar e aconselhar, sempre que possível, e de forma coerente com a ciência, outras pessoas que sintam a necessidade de buscar auxílio e ajuda quanto a problemas vivenciados sobre a temática.

Tais ações ainda se referem aos valores pessoais pelos quais os docentes passam e acabam assumindo, afinal estamos todos inseridos em um contexto. Diante disso, de acordo com Brol e Martelli (2018), as atividades de formação docente, sejam elas iniciais ou continuadas, que incitam reflexões sobre a não imposição de valores morais frente às manifestações dos alunos (e também dos professores), serão fundamentais, contribuindo para o desenvolvimento emancipatórios de todos os sujeitos envolvidos no processo de mediação do saber.

Apesar de diferenciarmos essas duas primeiras categorias, percebemos que algumas delas objetivaram trabalhar os dois aspectos, de sensibilização e de capacitação, simultaneamente: 
DOI: http://dx.doi.org/10.33238/ReBECEM.2019.v.3.n.3.23845

[...] visa sensibilizar e capacitar acadêmicos da área de saúde a fím de que formem atitudes e valores sadios em relação à sua sexualidade, bem como atuem como multiplicadores junto a escolares, grupo de gestantes, grupo de mães e adolescentes - A1.

As atividades desenvolvidas para diferentes públicos, visando mais disseminação da temática e ampliação das discussões que circundam a sexualidade, foram agrupadas na categoria 'Ampliação da visibilidade da temática'. Grande parte das atividades dessa categoria foram os eventos de cinema e, em sua maioria, também eram destinadas a discussões da diversidade sexual, à promoção do respeito e ao enfrentamento do preconceito.

A categoria 'Educar sexualmente' foi destinada às atividades de extensão que foram remetidas a um público específico (em sua maioria, adolescentes) de reconhecimento e de compreensão do próprio corpo, seus prazeres e suas relações com a sociedade, em geral, discussões e reflexões sobre sua própria sexualidade, no sentido instrutivo, da Educação Sexual propriamente:

[...] visa informar aos alunos do ensino médio das redes pública e privada da cidade de Cascavel as atitudes de risco que favorecem o contágio com uma DST, e o uso de métodos contraceptivos para promover prevenção DST e gravidez indesejada, respectivamente - A9.

Objetivo: Realizar práticas educativas, de orientação a adolescentes estudantes sobre a saúde sexual e reprodutiva e na prevenção das vulnerabilidades, com promoção de qualidade de vida - A41.

Percebemos que os objetivos das atividades incluem olhares diferentes conforme o público a que se destinam. Em sua ampla maioria, percebemos que as atividades visam, além de uma capacitação docente, uma nova forma de olhar e de conviver com os estudantes que constituem nossas diversidades humanas nos ambientes escolares.

\section{Considerações finais}

Ao observamos as tipologias das atividades, as áreas de estudo e os públicos-alvo, percebemos que grande parte das atividades possui vieses educacionais formativos, ou seja, a contribuição da extensão universitária para a sexualidade visa, em especial, educar sexualmente, tanto docentes quando alunos, sobre as problemáticas que envolvem tal temática. Em grande medida, a universidade pesquisada tende a socializar, a outros profissionais, os saberes produzidos academicamente, formando, assim, disseminadores de atitudes e de conhecimentos que serão efetivados em suas práticas escolares. 


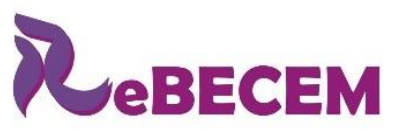

Revista Brasileira de Educação em

Ciências e Educação Matemática

DOI: http://dx.doi.org/10.33238/ReBECEM.2019.v.3.n.3.23845

Existe um amplo anseio da universalização da extensão universitária, e isso pode ser visto como uma forma efetiva de se caracterizar a indissociabilidade entre ensino, pesquisa e extensão universitária. Estudos e debates são, todavia, fundamentais para que sejam considerados o perfil e os vínculos dos docentes, estudantes e demais profissionais que trabalham nesse tripé.

Como expusemos, as atividades de extensão analisadas, elas, em sua maioria, objetivam a formação de profissionais multiplicadores da temática, incluindo o fornecimento de subsídio teórico-metodológico para abordá-la. São atividades de grande valia quando possibilitam, aos educadores da Educação Básica, aprimorarem as suas práticas educativas na busca pela formação de sujeitos ativos socialmente e que lutem pelos direitos humanos e civis de todas as pessoas.

As atividades de extensão universitária analisadas incitam reflexões que possibilitam o desenvolvimento e a ampliação de atitudes e de compreensões visando o respeito e a empatia, além de incitar que nossas formas de sermos no mundo e exercermos a/s nossa/s sexualidade/s são de direito e constituídas em nossas relações biológicas, psicológicas e sociais.

Quanto ao ano de início dos projetos, podemos observar que atitudes políticas e públicas que tenham ação sobre outras etapas de ensino também podem ser refletidas sobre o ensino superior e, consequentemente, sobre a extensão universitária. Por mais que essa etapa possua maior autonomia em diferentes âmbitos, percebemos o quanto ações inibidoras também possam incidir sobre ela.

O preparo dos profissionais da educação em todos os fatores aqui discutidos é essencial para que possam abordar os assuntos relacionados à sexualidade no contexto educativo. Entretanto, corroboramos o posicionamento de Pereira e Monteiro (2015) e de Oliveira e Maio (2012), bem como o de muitos outros autores, ao exporem que o estudo da sexualidade possui defasagem entre os professores, recomendando que esse estudo deva ser conteúdo de formação continuada e específica dos educadores.

Tal defesa está alicerçada na ideia de que embora as atividades analisadas estejam, em sua maioria, voltadas para a formação de professores, ainda percebemos, em pesquisas, que existe um amplo problema no processo tanto de formação docente inicial quanto no de formação continuada dos profissionais que abordam a temática. Há necessidade de investigações que indiquem possíveis caminhos para a melhoria da formação desses educadores, principalmente acerca do desenvolvimento e avaliação de práticas formativas docentes nessa temática, no âmbito do ensino. Salientamos que 


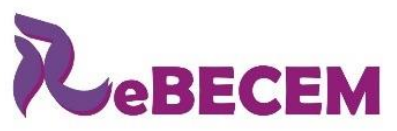

Revista Brasileira de Educação em

Ciências e Educação Matemática

ISSN 2594-9179

DOI: http://dx.doi.org/10.33238/ReBECEM.2019.v.3.n.3.23845

quanto às atividades extensionistas propostas pela universidade investigada devem, claramente, continuar sendo fomentadas e estimuladas a fim de ampliar os olhares e os níveis educativos a que se destinam as formações. Assim, indicamos a relevância de pesquisas acadêmicas em que a abordagem da temática sexualidade, na formação docente, se desenvolva no entrelaçamento com o ensino e a extensão.

\section{Referências}

BARDIN, L. Análise do conteúdo. 1. ed. São Paulo: Edições 70, 2016.

BRASIL. Presidência da República. Constituição da República Federativa do Brasil. Brasília/DF, 1988.

BRASIL. Lei $n^{\circ}$ 9.394, 20 de dezembro de 1996. Estabelece as diretrizes e bases da educação nacional. Brasília/DF, 1996.

BRASIL. Secretaria de Educação Fundamental. Parâmetros curriculares nacionais: primeiro e segundo ciclos do ensino fundamental ( $1^{\mathrm{a}}$ a $4^{\mathrm{a}}$ séries). Brasília/DF: MEC/SEF, 10 volumes, 1997.

BRASIL. Secretaria de Educação Fundamental. Parâmetros curriculares nacionais: terceiro e quarto ciclos do ensino fundamental ( $5^{\mathrm{a}}$ a $8^{\mathrm{a}}$ séries). Brasília/DF: MEC/SEF, 10 volumes, 1998.

BRASIL. Presidência da República. Lei no 13.005, de 25 de junho de 2014. Aprova o Plano Nacional de Educação - PNE e dá outras providências, Brasília/DF, 2014.

BROL, I. S.; MARTELLI, A. C. Abordagem da sexualidade nas formações continuadas de professores e professoras da rede básica de ensino. Revista Ártemis, João Pessoa, v. 25, n. 1, p. 274-291, jan./jun. 2018.

CARDOSO, J. C.; MWOLO, M. P. Assessment of non-formal sexual education strategies for adolescent girls: the case of Tanzania. Ensaio: Avaliação e Políticas Públicas em Educação, Rio de Janeiro, v. 25, n. 95, p. 527-547, abr. 2017.

ESPEJO, J. C. Disidencias sexuales en el sistema escolar chileno: represión e invisibilización. Educação e Pesquisa, São Paulo, v. 43, n. 3, p. 879-898, set. 2017.

FLICK, U. Introdução à pesquisa qualitativa. 3. ed. Porto Alegre, RS: Artmed, 2009.

FINCO, D. Gender equality in Brazilian early childhood educational institutions. Revista

Latinoamericana de Ciencias Sociales, Niñez y Juventud, Santiago de Chile, v. 13, n. 1, p. 85-96, 2015.

FOUCAULT, M. História da sexualidade I: A vontade de saber. 6. ed. Rio de Janeiro/São Paulo: Paz e Terra, 2017.

FURLANI, J. Educação sexual: possibilidades didáticas. In: LOURO, G. L.; NECKEL, J. F.; GOELLNER, S. V. (org.). Corpo, gênero e sexualidade: um debate contemporâneo na educação. 9. ed. Petrópolis, RJ: Vozes, 2013. p. 67-82. 
DOI: http://dx.doi.org/10.33238/ReBECEM.2019.v.3.n.3.23845

GOULART, A. T. A importância da pesquisa e da extensão na formação do estudante universitário e no desenvolvimento de sua visão crítica. Horizonte - Revista do Núcleo de Estudos em Teologia da Pontifícia Universidade Católica de Minas Gerais, Belo Horizonte, v. 2, n. 4 , p. $60-73,2004$.

HERNECK, H. R.; FERRACO, C. E.; TEIXEIRA, M. F. R. Sexualidade e educação: o Centro de Aconselhamento e Orientação de Jovens (CAOJ) de Coimbra-PT enquanto espaço de formação. Ciência \& Educação, Bauru, v. 23, n. 1, p. 111-124, mar. 2017.

JAEGER, A. A.; JACQUES, K. Masculinidades e docência na educação infantil. Revista Estudos Feministas, Florianópolis, v. 25, n. 2, p. 545-570, 2017.

LOURO, G. L. Pedagogias da sexualidade. In: LOURO, G. L. (org.). O corpo educado: pedagogias da sexualidade. Belo Horizonte, MG: Autêntica, 2000. p. 7-34.

LOURO, G. L. Gênero, sexualidade e educação: uma perspectiva pós-estruturalista. 16. ed. Petrópolis, RJ: Vozes, 2014.

MOITA, F. M. G. S. C.; ANDRADE, F. C. B. Ensino-Pesquisa-Extensão: um exercício de indissociabilidade na pós-graduação. Revista Brasileira de Educação, Rio de Janeiro, v. 14, n. 41, p. 269-280, maio/ago. 2009.

OLIVEIRA, M.; MAIO, E. R. Formação de professores/as para abordagem da educação sexual na escola. Revista Espaço Plural, v. 13, n. 26, p. 45-54, 2012.

PEIXOTO, R.; MAIO, E. R. Educação sexual na Educação Básica: dimensões pedagógicas entre a formação continuada, currículo escolar e aspectos socioculturais das relações humanas. In: PARANÁ, Secretaria de Estado da Educação. Superintendência de Educação. Os desafios da escola pública paranaense na perspectiva do professor PDE: produção didáticopedagógica, 2013. Curitiba: SEED/PR., 2016. v. 2. (Cadernos PDE).

PEREIRA, Z. M.; MONTEIRO, S. S. Gênero e sexualidade no ensino de ciências no Brasil: análise da produção científica recente. Revista Contexto \& Educação, v. 30, n. 95, p. 117-146, 2015.

PESSOA, A. S. G. et al. Resilience processes within the school context of adolescents with sexual violence history. Educação em Revista, Belo Horizonte/MG, v. 33, e157785, 2017.

REIS, T.; EGGERT, E. Ideologia de gênero: uma falácia construída sobre os planos de educação brasileiros. Educação \& Sociedade, Campinas, v. 38, n. 138, p. 9-26, jan./mar. 2017.

RIBEIRO, C. M. Crianças, gênero e sexualidade: realidade e fantasia possibilitando problematizações. Revista Estudos Feministas, Florianópolis, v. 19, n. 2, p. 605-614, 2011.

SILVA, D. R. Q.; SARMENTO, D. F.; FOSSATTI, P. Gênero e sexualidade: O que dizem as professoras de educação infantil de Canoas, Brasil? Archivos Analíticos de Políticas Educativas, Arizona, v. 20, n. 16, p. 1-20, 2012.

VIEIRA, P. M.; MATSUKURA, T. S. Modelos de educação sexual na escola: concepções e práticas de professores do ensino fundamental da rede pública. Revista Brasileira de Educação, Rio de Janeiro, v. 22, n. 69, p. 453-474, jun. 2017.

Recebido em: 09 de setembro de 2019.

Aceito em: 10 de dezembro de 2019. 